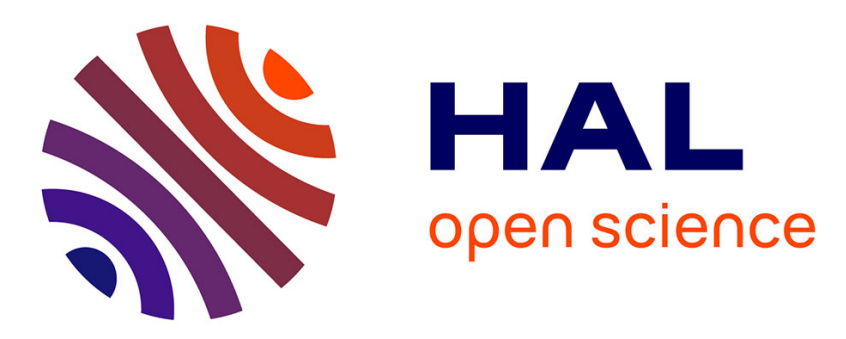

\title{
Surface modification of titania nanoparticles by catechol derivative molecules: Preparation of concentrated suspensions
}

Fadoua Sallem, Lucas Villatte, Pierre-Marie Geffroy, Graziella Goglio, Cécile

Pagnoux

\section{- To cite this version:}

Fadoua Sallem, Lucas Villatte, Pierre-Marie Geffroy, Graziella Goglio, Cécile Pagnoux. Surface modification of titania nanoparticles by catechol derivative molecules: Preparation of concentrated suspensions. Colloids and Surfaces A: Physicochemical and Engineering Aspects, 2020, 602, 125167 (9 p.). 10.1016/j.colsurfa.2020.125167 . hal-02885965

\section{HAL Id: hal-02885965 https://hal.science/hal-02885965}

Submitted on 18 Sep 2020

HAL is a multi-disciplinary open access archive for the deposit and dissemination of scientific research documents, whether they are published or not. The documents may come from teaching and research institutions in France or abroad, or from public or private research centers.
L'archive ouverte pluridisciplinaire HAL, est destinée au dépôt et à la diffusion de documents scientifiques de niveau recherche, publiés ou non, émanant des établissements d'enseignement et de recherche français ou étrangers, des laboratoires publics ou privés. 


\title{
Surface modification of titania nanoparticles by catechol derivative molecules: Preparation of concentrated suspensions
}

\author{
Fadoua Sallem ${ }^{\mathrm{a}}$, Lucas Villatte ${ }^{\mathrm{b}}$, Pierre-Marie Geffroy ${ }^{\mathrm{a}}$, Graziella Goglio ${ }^{\mathrm{b}}$, Cécile Pagnoux ${ }^{\mathrm{a}^{*}}$ \\ ${ }^{a}$ IRCER, Centre Européen De La Céramique, Université De Limoges, 12 Rue Atlantis 87068 Limoges, France \\ ${ }^{\mathrm{b}}$ CNRS, Université De Bordeaux, ICMCB, Institut De Chimie De La Matière Condensée De Bordeaux, UMR 5026, 87 Avenue Du Dr A. Schweitzer, 33608 Pessac, France \\ * Corresponding author : e-mail : cecile.pagnoux@unilim.fr
}

\section{Abstract}

This work focused on the preparation of high solid content suspension from nanosized $\mathrm{TiO}_{2} \mathrm{P} 25$ (about 30 nm). Two derivative catechol molecules (Tiron and Dopamine), were used as dispersants to enhance the colloidal stability of the prepared suspensions. Dopamine is a positively charged molecule which was used for the first time as dispersing agent and compared to Tiron, a negatively charged molecule. The effect of the pH and the dispersant percentage on the hydrodynamic size as well as on the surface chemistry of titania was studied in diluted suspension, using dynamic light scattering (DLS) and zeta potential measurements (acoustophoresis). Tiron and Dopamine adsorptions on titania surface were investigated using UV-vis spectrometry and thermogravimetric analyses (TGA). It was illustrated, from the rheological behavior, that Tiron and Dopamine decrease dramatically the viscosity of highly concentrated titania suspensions and allow to reach up to 15 vol\% and 20 vol\% for dopamine and tiron-modified titania suspensions.

Keywords : Nanosized titania, Suspension, Tiron, Dopamine, Surface modification

\section{Introduction}

Ceramics are interesting materials thanks to their low electrical and thermal conductivities, low density, wear and corrosion resistance as well as their mechanical strength at high temperature. However, their brittleness at low temperature is considered as their most disadvantage [1], this is why nanoceramics, ceramics obtained from nanosized grains, have attracted much attention during this last decades thanks to their ductility [2]. It is also well known that the use of ultrafine ceramics powders can also reduce the sintering temperature of ceramics and increase their density [3]. Thus, to prepare ceramics with high density and mechanical strength, green ceramic bodies should be densely packed which could be achieved by preparing well-dispersed ceramics suspensions during their colloidal processing. Indeed, nanoparticle agglomeration could induce flaws in the final product and hence reduces the mechanical strength and reliability of ceramics [4]. The preparation of suspensions consists in mixing ceramic powder in water or organic solvent with the use of some organic or inorganic additives such as dispersants, binders, etc [5].

Titanium dioxide is one of the most studied ceramics thanks to its optical properties. It is used for photocatalysis, photovoltaic, sensing and biomedical applications [6]. However, like most inorganic oxide materials, the preparation of well-dispersed titania suspension with high solid content from nanosized powder is crucial due to nanoparticles agglomeration, induced by the attractive Van der Waals forces interactions [7] as well as the high viscosity of the suspension, compared to micron sized powders [8,9]. To overcome these problems, it was proposed to use dispersing molecules which are able to modify the surface chemistry of titania nanoparticles and create repulsive forces (electrostatic or steric or the combination of both). The most used dispersants to enhance the colloidal stability of titania suspensions are polyelectrolytes such as polyacrylic acid (PAA), polystyrene sulfonate (PSS), polydially dimethyl ammonium chloride (PDADMAC) and polyamido amine dendrimer (PAMAM) [10]. Moreover, other dispersing agents like catechol derivative molecules have raised attention thanks to their high affinity for inorganic oxides by coordinating with the unsaturated atoms at their surfaces [11]. Indeed, the chemisorption of catechol molecules onto titania surface is explained by forming ligand-to-metal charge transfer complexes between the catechol (endiol) groups and the undercoordinated Ti atoms on the surface of the nanoparticles [12]. Among the catechol molecules, 4,5-dihydroxy-1,3-benzenedisulfonic acid disodium salt (Tiron) and 3,4-dihydroxyphenylethylamine (Dopamine) have been used to enhance the physico-chemical properties of titania nanoparticles for bio-sensing [13,14] and photocatalysis [15,16] applications. Among these two molecules, only Tiron has been used as dispersing agent to prepare titania suspensions with high solid content (up to 20 vol\%) from submicron sized particles $(0.4 \mu \mathrm{m})$ and with low viscosities [17,18]. However, Dopamine is used for the first time to prepare high solid content titania suspension. There are few studies that have discussed the flow behavior of nanosized titania suspensions [7,19]. This work shows for the first time the difference between two catechols, Tiron and Dopamine, used as dispersing agents for the preparation of nanosized titania suspension at high solid content. The difference of the colloidal behavior between Dopamine and Tiron-modified titania suspensions as well as their adsorption onto nanoparticle surface are detailed using various characterization techniques which are acoustophoresis, zeta potential and dynamic light scattering measurements, UV-vis spectrometry and rheological measurements. 


\section{Materials and methods}

\subsection{Chemicals}

Aeroxide $\mathrm{TiO}_{2} \mathrm{P} 25$ was provided by Evonik ( $>99.5 \%$, Germany). It is a mixture of rutile and anatase phases as it is shown in the Xray diffraction (XRD) pattern in the supplementary information (SI1). The phase quantification was carried out using Rietveld analysis method where the anatase represents the major crystallographic phase with $86.9 \%$ compared to only $13.1 \%$ of rutile. The specific surface area was measured using the Brunauer-Emmett-Teller (BET) method to about $60 \mathrm{~m}^{2} . \mathrm{g}^{-1}$. 4,5-Dihydroxy-1,3benzenedisulfonic acid disodium salt monohydrate (Tiron, $\mathrm{C}_{6} \mathrm{H}_{4} \mathrm{Na}_{2} \mathrm{O}_{8} \mathrm{~S}_{2} \cdot \mathrm{H}_{2} \mathrm{O}, 316$ g/mol), 3,4-Dihydroxyphenethylamine hydrochloride (Dopamine, $\mathrm{C}_{8} \mathrm{H}_{11} \mathrm{NO}_{2} \cdot \mathrm{HCl}, 189 \mathrm{~g} / \mathrm{mol}$ ), sodium chloride $(\mathrm{NaCl})$, hydrochloride acid solution $(\mathrm{HCl}, 1 \mathrm{~N})$ and sodium hydroxide $(\mathrm{NaOH}, \geq 98 \%)$ were provided by Sigma-Aldrich (Germany).

\subsection{Characterization techniques}

Scanning electron microscopy (SEM) used for the current study is IT300 instrument. The observation was operated at different accelerating voltages $(5-10 \mathrm{kV})$. A layer of about $15 \mathrm{~nm}$ of Au-Pd was deposited on the sample to ensure a suitable electronic conduction at the surface.

Transmission electron microscopy (TEM) characterization was carried out using a JEOL JEM 2100 F microscope operating at 200 KV (resolution of $0.19 \mathrm{~nm}$ ). The sample was prepared by dispersing the $\mathrm{TiO}_{2}$ nanoparticles in water and deposing a droplet on a carbon-coated copper grid.

X-Ray diffraction (XRD) pattern of $\mathrm{TiO}_{2}$ powder was performed using a Bruker D8 diffractometer with $\mathrm{Cu} \mathrm{K} \alpha$ radiation $\left(\lambda_{\mathrm{Cu}}=1.54056 \AA\right)$, at a step scan of 0.01 operated at a voltage of $40 \mathrm{KV}$ with an electric current of $40 \mathrm{~mA}$ and over the $2 \theta$ range from 20 to $90^{\circ}$.

Zeta potential measurements and particles size measurements were carried out by Acoustosizer (Colloidal Dynamics, MA) for $120 \mathrm{~mL}$ of 1 vol\% of titania suspension. The principle of acoustosizer is based on generating sinusoidal voltage pulses over a frequency range 1-20 MHz. These pulses generate, in the colloid, ultrasonic signals which contain information about the particle size and charge. The ionic strength was fixed by $\mathrm{NaCl}\left(10^{-2} \mathrm{M}\right.$ in the final suspension) and the titration was carried out using titrating syringes $(1 \mathrm{M} \mathrm{HCl}$ and $1 \mathrm{M} \mathrm{NaOH}$ ) over a suitable $\mathrm{pH}$ range (from 2 to 10.5). The titration was begun from low $\mathrm{pH}$ value because the natural $\mathrm{pH}$ of titania suspension is 3.5 . The zeta potential measurements accuracy was evaluated to $\pm 2 \mathrm{mV}$.

Dynamic Light Scattering (DLS) measurements were carried out using zetasizer (Malvern, UK) to measure the hydrodynamic diameters $\mathrm{TiO}_{2}$ nanoparticles. The DLS measurements were performed for diluted $\mathrm{TiO}_{2}$ suspensions $(0.3 \mathrm{mg} / \mathrm{mL})$ in order to avoid interactions between nanoparticles and repeated three times at $25.0^{\circ} \mathrm{C}$. The mean size were derived from the numbers distribution, calculated on the same instrument.

UV-vis absorbance was measured using Varian Cary-5000 spectrometer at $280 \mathrm{~nm}$ for Dopamine and $291 \mathrm{~nm}$ for Tiron in aqueous solution. Dopamine and Tiron quantification was carried out using calibration curves.

The rheological measurements of the prepared suspensions were carried out using a rheometer (AR1500, TA Instruments, USA) operating at a controlled-stress and using a double-cone and plate system (diameter $4 \mathrm{~cm}$; angle $2^{\circ}$ ). The flow behavior of the freshly prepared suspensions were followed up while imposing a linear stress ramp from 0 to $20 \mathrm{~Pa}$ and decreasing to $0 \mathrm{~Pa}$, at $25^{\circ} \mathrm{C}$ for $2 \mathrm{~min}$.

Thermogravimetric analyses (TGA) were carried out using Setarem Instrumentation under an air flow rate of $20 \mathrm{~mL} . \mathrm{min}^{-1}$. The analyses were performed using the following thermal program: ramp 1 of $10^{\circ} \mathrm{C} \cdot \mathrm{min}^{-1}$ from $20^{\circ} \mathrm{C}$ to $30{ }^{\circ} \mathrm{C}$, isotherm at $30{ }^{\circ} \mathrm{C}$ for $30 \mathrm{~min}$ and ramp 2 of $10^{\circ} \mathrm{C} . \mathrm{min}^{-1}$ from $30{ }^{\circ} \mathrm{C}$ to $800^{\circ} \mathrm{C}$.

\subsection{Preparation of titania suspension}

For Dopamine-modified titania suspension, the appropriate amount of titania powder was mixed with demineralized water, at different $\mathrm{TiO}_{2}$ /water volume ratio (1-20 vol\%), where the corresponding dispersant amount (0-1.75 wt\% of titania mass) was previously dissolved. The $\mathrm{pH}$ of the suspensions was adjusted by adding $\mathrm{NaOH}$ solution $(1 \mathrm{M})$, and the deagglomeration of the nanoparticles was carried out using the sonication.

For Tiron-modified titania suspension, Tiron was first dissolved in demineralized water and the $\mathrm{pH}$ was adjusted to 9 by adding $\mathrm{NaOH}$ solution $(1 \mathrm{M})$. Then titania powder was added gradually and using sonication when the suspension became viscous. The $\mathrm{pH}$ was controlled by adding $\mathrm{NaOH}$ solution $(1 \mathrm{M})$. 
The point of zero charge (PZC) of $\mathrm{TiO}_{2}$ was determined as follows: $0.5 \mathrm{~g}$ of each powder was added to $25 \mathrm{~mL}$ of $0.01 \mathrm{M} \mathrm{NaCl}$ solutions where the initial $\mathrm{pH}\left(\mathrm{pH}_{\mathrm{i}}\right)(0.01 \mathrm{M} \mathrm{NaCl}$ solutions) was previously adjusted between 3 and 9 . The suspensions were stirred for $24 \mathrm{~h}$ at $25^{\circ} \mathrm{C}$ and then the final $\mathrm{pH}\left(\mathrm{pH}_{\mathrm{f}}\right)$ was measured. The intersection between the variation of the $\mathrm{pH}\left(\Delta \mathrm{pH}: \mathrm{pH}_{\mathrm{f}}-\mathrm{pH}_{\mathrm{i}}\right)$ versus the initial $\mathrm{pH}_{\mathrm{i}}$ gives the point of zero charge.

\subsection{Study of the adsorption of Tiron and Dopamine onto titania nanoparticles}

\subsubsection{Dispersant adsorption as a function of the dispersant percentage}

The adsorption study of the dispersant (Dopamine or Tiron) was carried out using titania suspensions at $2 \mathrm{vol} \%$ of $\mathrm{TiO}_{2}$. The studied Dopamine and Tiron percentages are set between $0 \mathrm{wt} \%$ and $1.75 \mathrm{wt} \%$ and the adsorption time at $24 \mathrm{~h}$. The appropriate amounts of Dopamine and Tiron were collected from freshly prepared stock solution $\left(20 \mathrm{~g} . \mathrm{L}^{-1}\right)$ and added to $5 \mathrm{~mL}$ of titania suspensions previously prepared at the appropriate $\mathrm{pH}(3,7$ and 9). In order to determine the initial dispersant concentration, blanks are prepared in the same conditions as the samples but without titania. All the samples are left under mechanical stirring for $24 \mathrm{~h}$. At the end of the reaction, the dispersant-modified titania suspensions are filtered and the dispersant concentrations are determined by measuring the absorbance of the filtered solutions at $291 \mathrm{~nm}$ for Tiron and $280 \mathrm{~nm}$ for Dopamine and using calibration curves, previously performed in the same studied $\mathrm{pH}$ (pH 3 for Dopamine and $\mathrm{pH} 7$ and 9 for Tiron).

The kinetics of dispersant adsorption onto titania nanoparticle surface was studied for six suspensions prepared as follow: 2 vol\% titania suspension with $1 \mathrm{wt} \%$ and $1.5 \mathrm{wt} \%$ of dispersant, at fixed $\mathrm{pH}$ (pH 3 for Dopamine and $\mathrm{pH} 7$ and 9 for Tiron). The initial concentration of dispersant was determined using calibration curves at different times: $0,3,5,8$ and $24 \mathrm{~h}$.

\section{Result and discussion}

\subsection{Characterization of $\mathrm{TiO}_{2} \mathrm{P} 25$ suspension}

The average size and the morphology of Evonik Aeroxide TiO2 P25 nanoparticles are obtained by SEM and TEM images (Fig. 1). The morphology of the nanoparticles is quasi-spheric with an average size of about $26 \pm 7 \mathrm{~nm}$. However, the TEM images highlight the presence of amorphous phase at the surface of the nanoparticles and randomly shaped nanoparticles (triangle, square, rectangle...) (Fig. 1D).

The presence of amorphous phase in Aeroxide P25 powder was also reported in previous works in literature [20] and quantified to $7 \%$ in the study of Jiang et al. [21]. The assessment of $\mathrm{TiO}_{2}$ size and surface charge as a function of the $\mathrm{pH}$ is carried out by acoustophoresis measurements as shown in Fig. 2. The acoustophoresis method evaluates the zeta potential and the size of particles in concentrated suspensions. It shows an isoelectric point (IEP) at 6.2 and maximum zeta potential values at about $\pm 40 \mathrm{mV}$. The IEP is measured between 6 and 7 which is in agreement with those reported in literature for $\mathrm{TiO}_{2}$ powder $[19,22,23]$. In order to check the homogeneity of the surface charge distribution, the point of the zero charge (PZC) of bare titania was determined using a potentiometric method (supplementary materials, Fig. SI2). The result shows that the PZC is equal to IEP which is 6.2. This confirm that there is no specific adsorption of counter ions from the solution [24]. It should be noted that the natural $\mathrm{pH}$ of 1 vol\% of titania suspension is 3.5 which can be due the synthesis process of this powder that probably uses hydrochloric acid. It should be noted that the protonation and deprotonation of the hydroxyl groups on the bare titania surface $(\mathrm{Ti}-\mathrm{OH})$ govern its surface charge. Indeed, a positive charge is generated at acidic condition and negative charge at basic medium due to $\mathrm{TiOH}_{2}{ }^{+}$and $\mathrm{TiO}^{-}$groups respectively [7]. Fig. 2 shows also the evolution of the nanoparticles size (d85) as a function of the pH (D85 means that the size of $85 \%$ of particles is less than this value). This figure illustrates the increase of the hydrodynamic size of nanoparticles due to their agglomeration when the $\mathrm{pH}$ of the suspension approaches to the IEP (6.2), however it does not decrease at high $\mathrm{pH}(\mathrm{pH}>$ IEP). It should be noted that the increases in the $\mathrm{pH}$ by $\mathrm{NaOH}$ addition increases even slightly the ionic strength in the suspension which leads to nanoparticles agglomeration [25]. This result assumes that the phenomenon of nanoparticle deagglomeration is not completely reversible which could limits the $\mathrm{pH}$ range of the colloidal stability of suspension and proves the necessity to add a dispersant molecule in order to enhance the nanoparticle dispersion.

\subsection{Dispersant effect on titania properties}

Dopamine and Tiron are used to enhance the colloidal stability of titania nanoparticles in order to prepare concentrated suspensions. Fig. 3 illustrates the interaction between the titania nanoparticle surface and the dispersants. Fig. 4 shows the evolution of the zeta potential as a function of the mass percentage of Dopamine and Tiron where the two dispersants show an antagonistic effects. From 
one hand, the negatively charged Tiron, due to the presence of two sulfonate groups (Fig. 3), decreases gradually the IEP from 6.2 to less than 2 when Tiron percentage increases from 0 to $1.75 \mathrm{wt} \%$ and inverses the global positive charge onto titania nanoparticle surface at low pH (2-6) to negative (Fig. 4A). The shift of the IEP due to the presence of Tiron was also reported in the study of Navizi et al. with hydroxyapatite [26]. On the other hand, the positively charged Dopamine neutralizes the negative charge of titania surface, at high $\mathrm{pH}$, inverses its global charge to positive charge for a wide range of $\mathrm{pH}(2-10)$ and increases gradually its IEP from 6.2 for $0 \mathrm{wt} \%$ to 9.9 for $1.75 \mathrm{wt} \%$ Dopamine (Fig. 4B).

The gradual change in the zeta potential with the increase of the mass ratio of Dopamine or Tiron, as it is shown in Fig. 4 illustrates that these two molecules cover progressively the surface of titania as a function of their percentages. It is noted here that the maximum zeta potential values, obtained at high $\mathrm{pH}(\mathrm{pH}>8)$, are larger for Tiron -modified nanoparticles than Dopamine-modified ones since at this range of $\mathrm{pH}$, the sulfonate groups are negatively charged compared to non-charged amine groups (Fig. 3).

In order to prepare titania suspensions with high solid content and low viscosity, the nanoparticles size must be adjusted since the viscosity of the suspensions is toughly related to the particle size [27]. Indeed, to obtain a good nanoparticle dispersion, it is important to prevent their agglomeration by optimizing the $\mathrm{pH}$ and the dispersant mass percentage. The nanoparticles size was measured at four chosen $\mathrm{pH}$ which are $\mathrm{pH} \mathrm{3,5,7}$ and 9 and as a function of mass dispersant percentage (Tiron and Dopamine) to provide the ideal $\mathrm{pH}$ range and the best formulation for the preparation of concentrated titania suspension. Fig. 5 presents the hydrodynamic size measurements vs dispersant percentage, measured by zetasizer in diluted suspensions because it is more accurate that acoustosizer for nanosized particles. Fig. 5A shows that the hydrodynamic diameter of Dopamine-modified titania is about $100 \mathrm{~nm}$ at $\mathrm{pH} 3$ and 5. This size is slight higher than that noted for bare nanoparticles (about $83 \mathrm{~nm}$ ) which could be explained by the titania polydispersity in this condition due to the increase of the ionic strength which leads to the particles aggregation [28]. However, the hydrodynamic size increases dramatically at $\mathrm{pH} 7$ and 9 to above $1 \mu \mathrm{m}$ for all studied Dopamine/titania mass ratios. This result can be explained by the fact that Dopamine increases the IEP of titania to above 7, as it is shown in Fig. 4 so that the nanoparticles agglomerate at this $\mathrm{pH}$ range. Fig. $5 \mathrm{~B}$ shows that the evolution of the nanoparticles size of Tiron-modified titania is different from that obtained for Dopamine. At acidic conditions ( $\mathrm{pH} 3$ and 5), the nanoparticles agglomerate as the IEP is close to the studied $\mathrm{pH}$ (Fig. 4) for the major Tiron/titania mass ratio. However, at $\mathrm{pH} 7$ and 9, the hydrodynamic size decreases from $1.25 \mu \mathrm{m}$ for $0 \mathrm{wt} \%$ to $320 \mathrm{~nm}$ for $0.5 \mathrm{wt} \%$ of Tiron since the zeta potential values of Tiron-modified titania at these conditions $(>0.5 \mathrm{wt} \%$ Tiron, $\mathrm{pH}>7$ ) increases in absolute value to about $-25 \mathrm{mV}$ (Fig. 4). The nanoparticle size decreases to about $120 \mathrm{~nm}$ from $1 \mathrm{wt} \%$ of Tiron at $\mathrm{pH} 7$ and 9 which makes these two $\mathrm{pH}$ promising to prepare concentrated suspensions with low viscosity. The high surface charge of modified titania disaggregates the nanoparticles and decreases their size. In conclusion, Dopamine stabilizes titania nanoparticles in acidic medium $(\mathrm{pH}<5)$ and Tiron at basic conditions $(\mathrm{pH}>7$ for Tiron/titania mass ratio $>1 \mathrm{wt} \%)$.

From the zeta titration curves in Fig. 4, it is noted that the zeta potential becomes independent of the $\mathrm{pH}(\mathrm{pH}<5$ for Dopamine and $\mathrm{pH}>7$ for Tiron), because it reaches a limit value ( $+40 \mathrm{mV}$ for Dopamine and $-45 \mathrm{mV}$ for Tiron). However, Fig. 5 shows that the hydrodynamic size of nanoparticles strongly depends on the $\mathrm{pH}$ of the suspension. This implies that the high zeta potential, close to the nanoparticle surface, is not the only criterion to obtain a good colloidal stability of the suspension. Then, the impact of the dispersant adsorption on the titania suspension stability is investigated in the next section.

\subsection{Study of the dispersant adsorption on titania surface}

The first experiment consists in evaluating the adsorbed amount of each dispersant as a function of dispersant/titania mass ratio $(\mathrm{pH}$ 3 for Dopamine and $\mathrm{pH} 7$ and 9 for Tiron). The choice of the $\mathrm{pH}$ is based on the results discussed in the previous section (Fig. 4 , Fig. 5) where the dispersant-modified $\mathrm{TiO}_{2}$ particles present the highest zeta potential values and the lowest hydrodynamic size.

Fig. 6A shows the adsorption rate (\%) of Dopamine at $\mathrm{pH} 3$ and Tiron at $\mathrm{pH} 7$ and 9. The rate of Dopamine adsorption decreases continuously from $85.7 \%-40.1 \%$ when the Dopamine percentage increases from 0.25 to $1.75 \mathrm{wt} \%$. The similar trend is observed for the adsorption of Tiron where the adsorption rate decreases also with Tiron percentages, but with different behavior. Indeed, at $\mathrm{pH}$ 7, Tiron adsorption rate is almost constant at about $100 \%$ for dispersant content in the range between 0.25 and $0.75 \mathrm{wt} \%$ and then decreases to $60 \%$ for $1.75 \mathrm{wt} \%$ of Tiron. Tiron adsorption rate at $\mathrm{pH} 9$ has the same behavior as that noted for $\mathrm{pH} 7$ but with lower adsorption rate in the range between 0.25 and $0.75 \mathrm{wt}$ where it varies from 81.9-85.3\% and then decreases slowly to $67.2 \%$ for $1.75 \mathrm{wt} \%$ (Fig. 6A). The low adsorption rate observed for Tiron-modified titania at $\mathrm{pH}=9$ at low Tiron content $(0.25-0.75 \mathrm{wt} \%)$ could be due to the electrostatic repulsion force between the negatively charged Tiron and titania surface. This repulsion force is less accentuated at $\mathrm{pH}=7(0-0.75 \mathrm{wt} \%$ Tiron $)$ as the titania surface still has positive charges that promote the electrostatic attraction between Tiron and titania, allowing a better dispersant adsorption. However, Tiron adsorption rate decreases continuously at high Tiron percentages $(1-1.75 \mathrm{wt} \%)$ in the same way and with the same behavior for both $\mathrm{pH}$ (Fig. 6A). This could be related to the 
important amount of Tiron in the suspension and thus the high concentration of negative groups which neglects the electrostatic attraction with titania surface. Indeed, previous works proved that catechol molecules exhibit a very important complexing effect to metal oxide surfaces despite the repulsive forces. [29,30] On the other side, Fig. 6B shows the adsorbed amount of Dopamine and Tiron, expressed in molecule. $\mathrm{nm}^{-2}$, as a function of their percentage. It illustrates an increase in the amount of the adsorbed dispersant on titania nanoparticle surface with the dispersant percentage. The dispersant adsorption reaches an adsorption limit at $1.25 \mathrm{wt} \%$ and reaches 0.06, 0.033 and 0.029 molecule. $\mathrm{nm}^{-2}$ for Dopamine at $\mathrm{pH} 3$, and Tiron at $\mathrm{pH} 9$ and $\mathrm{pH} 7$ respectively. These results confirm that the surface of $\mathrm{TiO}_{2}$ nanoparticles is entirely covered by dispersant molecules when their amount achieves a critical value which is $1.5 \mathrm{wt} \%$ in both cases. The adsorption saturation of dispersant on titania nanoparticle surface was also reported in the work of Murata et al. for the adsorption of catechol molecule (2-hydroxyphenol) [13]. It is observed also that the adsorption rate of Tiron is higher than that of Dopamine (Fig. 6A) since the initial molar concentration of Tiron is lower than that of Dopamine which also explains the high adsorbed amount of Dopamine compared to that of Tiron.

The adsorption of Tiron and Dopamine was monitored over the time (0-24 hours) as it is reported in Fig. SI3 (supplementary information). This experiment shows that the maximum of dispersant adsorption is reached within $5 \mathrm{~h}$. Above $5 \mathrm{~h}$, the adsorption rates are similar, which proves that the complex titanium-catechol is formed immediately in the few first hours of the reaction. However, this experiment do not confirm that the chemisorption of dispersants is irreversible. Indeed, an adsorption equilibrium between the adsorbed and the desorbed amount of dispersant molecules could happen during the time.

To confirm if Tiron and Dopamine adsorption on titania surface is irreversible, Tiron/Dopamine-modified titania samples were washed two times with pure water in order to remove the excess of dispersant in the suspension and keep only the chemisorbed molecules on the surface. The adsorbed organic molecules were quantified by thermogravimetric analyses (TGA) (through the weight losses obtained between 200 and $450^{\circ} \mathrm{C}$ ). The results, obtained by TGA method, are compared to the spectrometric method, used in Section 3.3, and presented in Fig. 7. It is noted from this figure that the adsorbed amount of dopamine, calculated from TGA, is higher than that obtained for Tiron in both $\mathrm{pH}$ which is in agreement with spectrometric results (Figs. 6B and 7). Moreover, Fig. 7 illustrates a similarity in the amounts of adsorbed dispersants, measured by the two methods, which suggests that the adsorption phenomenon here is irreversible.

\subsection{Dispersant effect on titania suspension flow behavior}

The dispersant effect on the rheological characteristics of titania suspensions is reported in Fig. 8. It shows the impact of the dispersant add on the viscosity of concentrated titania suspension. Indeed, Dopamine decreases the viscosity of 12 vol\% Dopaminemodified titania suspension to 0.03 Pa.s compared to 2.8 Pa.s for the same titania suspension without Dopamine at $10 \mathrm{~s}^{-1}$ shear rate (Fig. 8A). The same effect is observed for Tiron which reduces the viscosity of 8 vol\% of Tiron-modified titania suspension to 0.03 Pa.s compared to 5.4 Pa.s for 8 vol\% of bare titania suspension at $10 \mathrm{~s}^{-1}$ shear rate (Fig. 8B). The effect of Tiron on the rheological behavior of high solid content titania suspensions has been already reported in literature [26] however that of Dopaminemodified titania suspension is reported for the first time in this study.

Fig. 9A reports the viscosity evolution in relation with shear rate for $15 \mathrm{vol} \%$ of dispersant-modified titania suspensions at 1 and $1.5 \mathrm{wt} \%$, at $\mathrm{pH} 3$ for Dopamine, and $\mathrm{pH} 7$ or 9 for Tiron. All suspensions exhibit a shear thinning behavior for the whole studied shear rate range except for Tiron-modified titania suspensions ( $\mathrm{pH} 7$ ), which show plastic behavior and high viscosity. For a shear rate below $1 \mathrm{~s}^{-1}$, Tiron-modified titania suspensions at $\mathrm{pH} 7$ show a Newtonian flow and high viscosity, because these suspensions behave as structured fluids due to the high interaction between nanoparticles, leading to their agglomeration. This assumes that at high solid content, nanoparticles behave differently than in diluted medium. This could be explained by the fact that the particles size at $\mathrm{pH} 7$ is higher than that obtained at $\mathrm{pH} 9$ as it was shown in Fig. 2 for bare titania suspension at 1\%vol. Indeed, it was reported in the study of G. Trefalt et al. that the particles/aggregates size is proportional to the interaction free energy where the higher is the size of aggregates, the higher are the inter-particles interactions [31]. Moreover, it is noted also that at $\mathrm{pH} 7$ there is simultaneous presence of positive and negative charges, which increases the electrostatic interactions and consequently the agglomeration of nanoparticles.

At $\mathrm{pH}$ 9, titania suspensions are much more fluid than those at pH 7. Indeed, it is well known that the particles size increases with the ionic strength in the suspension [32]. It should be noted here that despite the increase in the ionic strength for Tiron-modified suspensions at $\mathrm{pH} 9$, due to $\mathrm{NaOH}$ addition, the suspensions viscosity decreases significantly compared to that obtained at $\mathrm{pH} 7$. The suspensions stability in these conditions could be explained by the highly negative surface of nanoparticles that induces strong electrostatic repulsion. 
On the other hand, Dopamine-modified titania suspensions at pH 3 are more viscous than those of Tiron-modified titania suspension at $\mathrm{pH}$ 9. This result could be explained by the fact that the charge density at Dopamine-modified nanoparticles surface at $\mathrm{pH} 3$ is lower than that of Tiron-modified nanoparticles at $\mathrm{pH} 9$ due to the presence of two negatively charged sulfonate groups in Tiron molecule compared to only one positively charged amine group in Dopamine. The difference between these two kinds of suspensions is pronounced at more important solid content condition (20 vol\%) as shown in Fig. 9B. Indeed, for 20 vol\% of titania concentration, the viscosity of Dopamine-modified titania suspension increases compared to that observed for 15 vol\%. This result is observed only for Dopamine-modified titania suspensions, however, not a big difference is noted for Tiron-modified titania suspension when the solid content increase from 15 vol\% to 20 vol\% (Fig. 9B). The difference in the rheological behavior between the two formulations at high solid content could support different explanations. From one hand, the presence of alkyl chain in dopamine molecule increases its hydrophobicity, which destabilizes titania suspensions as it was reported in the work of P. Rouster et al. [25]. On the other hand, it could be related to the presence of different kind of counter-ions in each formulation. Indeed, it should be noted that the counter-ion present in Tiron-modified titania suspensions is sodium cation $\left(\mathrm{Na}^{+}\right)$, compared to chloride anions $\left(\mathrm{Cl}^{-}\right)$for Dopamine-modified titania suspensions. In contrast to sodium ion, chloride anion is considered as structure breaker ion that disorder water structure, so weakens the hydrogen bond with water molecules [33,34]. This reduces the hydration layer around the nanoparticles and increases the inter-particle interactions.

Fig. 9B shows also that $1.5 \mathrm{wt} \%$ Dopamine stabilizes better titania suspensions than $1 \mathrm{wt} \%$ Dopamine and leads to lower viscosity values despite the increase in the electrolyte concentration and consequently in the ionic strength. This result suggests that the abundant presence of organic molecules onto nanoparticles surface (Fig. 7) improves the sliding phenomenon between nanoparticles and add a steric repulsion to the repulsive one which led to high resistance against the salt-induced aggregation as it was also reported in the work of S. Saringer et al. [35]. We conclude from the previous observations that Dopamine and Tiron can be used as dispersing agents for acidic and basic conditions respectively, and both of them enhance the flow behavior of titania suspensions at high solid content (up to 20 vol\% for Tiron-modified titania and up to 15 vol\% for Dopamine-modified titania).

\section{Conclusion}

In this work, we have discussed the preparation of titania suspensions with high solid content (up to 20 vol\% of titania) from nanosized titania powder of about $30 \mathrm{~nm}$. Two catechol molecules were proposed as dispersing agents to enhance the colloidal stability and the rheological behavior of highly concentrated titania suspensions. The dispersion conditions such as the dispersant mass percentages and the $\mathrm{pH}$ were optimized on diluted suspensions using DLS and zeta potential measurements. It was found that dispersant mass percentage above $1 \mathrm{wt} \%$ is required, for both dispersants, to enhance the colloidal stability and to prevent the agglomeration of nanoparticles. Moreover, the results give an evidence that a low $\mathrm{pH}(\mathrm{pH}<5)$ of the titania suspension is needed for Dopamine-modified titania suspensions, while high $\mathrm{pH}(\mathrm{pH}>7)$ is required for Tiron-modified titania suspensions. Two different adsorption rates and rheological behavior were discussed between the two studied dispersing agents. Stable titania nanoparticle suspensions were prepared with up to 15 and $20 \mathrm{vol} \%$ of solid content for Dopamine and tiron-modified titania suspensions, respectively. With such a solid content, suspensions have to be easily used for titania nanoparticles shaping such as granulation or pressure slip casting.

CRediT authorship contribution statement : Fadoua Sallem: Investigation. / Lucas Villatte: Resources / Pierre-Marie Geffroy: Funding acquisition, Supervision, Validation / Graziella Goglio: Funding acquisition, Project administration / Cécile Pagnoux: Funding acquisition, Conceptualization, Supervision.

\section{Declaration of Competing Interest}

The authors declare that they have no known competing financial interests or personal relationships that could have appeared to influence the work reported in this paper.

\section{Acknowledgments}

Authors would like tothank the French National Centre for Scientific Research (CNRS) and the University of Limoges for the financial support. We thank also Pierre Carle and Patrice Duport for transmission electron microscopy and scanning electron microscopy observations respectively and Richard Mayet for XRD analysis.

Appendix A. Supplementary data : Supplementary material related to this article can be found, in the online version, at doi:https://doi.org/10.1016/j.colsurfa.2020.125167. 


\section{References}

1) D. Munz, T. Fett. Ceramics: Mechanical Properties, Failure Behaviour, Materials Selection. Springer Science \& Business Media (2013)

2) J. Karch, R. Birringer, H. Gleiter. Ceramics ductile at low temperature. Nature, 330 (1987), pp. 556-558, 10.1038/330556a0

3) R. Chaim, M. Levin, A. Shlayer, C. Estournes. Sintering and densification of nanocrystalline ceramic oxide powders: a review. Adv. Appl. Ceram., 107 (2008), pp. 159-169, 10.1179/174367508X297812

4) R. Greenwood, K. Kendall. Selection of suitable dispersants for aqueous suspensions of zirconia and titania powders using acoustophoresis. J. Eur. Ceram. Soc., 19 (1999), pp. 479-488, 10.1016/S0955-2219(98)00208-8

5) C.-C. Li, S.-J. Chang, C.-W. Wu, C.-W. Chang, R.-H. Yu. Newly designed diblock dispersant for powder stabilization in waterbased suspensions. J. Colloid Interface Sci., 506 (2017), pp. 180-187, 10.1016/j.jcis.2017.07.045

6) X. Chen, S.S. Mao. Titanium dioxide nanomaterials: synthesis, properties, modifications, and applications. Chem. Rev., 107 (2007), pp. 2891-2959, 10.1021/cr0500535

7) H.S. Bae, M.K. Lee, W.W. Kim, C.K. Rhee.Dispersion properties of TiO2 nano-powder synthesized by homogeneous precipitation process at low temperatures. Colloids Surf. A Physicochem. Eng. Asp., 220 (2003), pp. 169-177, 10.1016/S0927-7757(03)00077-3

8) S. Çınar, D.D. Anderson, M. Akinc. Influence of bound water layer on the viscosity of oxide nanopowder suspensions. J. Eur. Ceram. Soc., 35 (2015), pp. 613-622, 10.1016/j.jeurceramsoc.2014.09.031

9) J. Chevalier, O. Tillement, F. Ayela. Rheological properties of nanofluids flowing through microchannels. Appl. Phys. Lett., 91 (2007), Article 233103, 10.1063/1.2821117

10) S. Muráth, S. Sáringer, Z. Somosi, I. Szilágyi. Effect of ionic compounds of different valences on the stability of titanium oxide colloids. Colloids Interfaces, 2 (2018), p. 32, 10.3390/colloids2030032

11) W. Macyk, K. Szaciłowski, G. Stochel, M. Buchalska, J. Kuncewicz, P. Łabuz. Titanium(IV) complexes as direct TiO2 photosensitizers. Coord. Chem. Rev., 254 (2010), pp. 2687-2701, 10.1016/j.ccr.2009.12.037

12) L. de la Garza, Z.V. Saponjic, N.M. Dimitrijevic, M.C. Thurnauer, T. Rajh. Surface states of titanium dioxide nanoparticles modified with enediol ligands. J. Phys. Chem. B, 110 (2006), pp. 680-686, 10.1021/jp054128k

13) Y. Murata, H. Hori, A. Taga, H. TadaSurface charge-transfer complex formation of catechol on titanium(IV) oxide and the application to bio-sensing. J. Colloid Interface Sci., 458 (2015), pp. 305-309, 10.1016/j.jcis.2015.07.065

14) M.S. Ata, Y. Liu, I. Zhitomirsky. A review of new methods of surface chemical modification, dispersion and electrophoretic deposition of metal oxide particles. RSC Adv., 4 (2014), pp. 22716-22732, 10.1039/C4RA02218A

15) B. Yao, C. Peng, P. Lu, Y. He, W. Zhang, Q. Zhang. Fabrication of Tiron-TiO2 charge-transfer complex with excellent visible-light photocatalytic performance. Mater. Chem. Phys., 184 (2016), pp. 298-305, 10.1016/j.matchemphys.2016.09.056

16) Dynamics of Localized Charges in Dopamine-Modified TiO2 and their Effect on the Formation of Reactive Oxygen Species, (n.d.). https://doi.org/10.1021/ja807654k.

17) S. Lebrette, C. Pagnoux, P. Abélard. Fabrication of titania dense layers by electrophoretic deposition in aqueous media. J. Eur. Ceram. Soc., 26 (2006), pp. 2727-2734, 10.1016/j.jeurceramsoc.2005.05.009

18) S. Lebrette, C. Pagnoux, P. Abélard. Stability of aqueous TiO2 suspensions: influence of ethanol. J. Colloid Interface Sci., 280 (2004), pp. 400-408, 10.1016/j.jcis.2004.07.033

19) S. Fazio, J. Guzmán, M.T. Colomer, A. Salomoni, R. Moreno. Colloidal stability of nanosized titania aqueous suspensions. J. Eur. Ceram. Soc., 28 (2008), pp. 2171-2176, 10.1016/j.jeurceramsoc.2008.02.017

20) J. Soria, J. Sanz, M.J. Torralvo, I. Sobrados, C. Garlisi, G. Palmisano, S. Çetinkaya, S. Yurdakal, V. Augugliaro. The effect of the surface disordered layer on the photoreactivity of titania nanoparticles. Appl. Catal. B, 210 (2017), pp. 306-319, 10.1016/j.apcatb.2017.03.045

21) X. Jiang, M. Manawan, T. Feng, R. Qian, T. Zhao, G. Zhou, F. Kong, Q. Wang, S. Dai, J.H. Pan. Anatase and rutile in evonik aeroxide P25: Heterojunctioned or individual nanoparticles? Catal. Today, 300 (2018), pp. 12-17, 10.1016/j.cattod.2017.06.010 
22) K. Sato, J.-G. Li, H. Kamiya, T. Ishigaki. Ultrasonic dispersion of TiO2 nanoparticles in aqueous suspension. J. Am. Ceram. Soc., 91 (2008), pp. 2481-2487, 10.1111/j.1551-2916.2008.02493.x

23) M. KosmulskiThe significance of the difference in the point of zero charge between rutile and anatase. Adv. Colloid Interface Sci., 99 (2002), pp. 255-264, 10.1016/S0001-8686(02)00080-5

24) H.N. Tran, S.-J. You, A. Hosseini-Bandegharaei, H.-P. Chao. Mistakes and inconsistencies regarding adsorption of contaminants from aqueous solutions: a critical review. Water Res., 120 (2017), pp. 88-116, 10.1016/j.watres.2017.04.014

25) P. Rouster, M. Pavlovic, T. Cao, B. Katana, I. Szilagyi. Stability of titania nanomaterials dispersed in aqueous solutions of ionic liquids of different alkyl chain lengths. J. Phys. Chem. C., 123 (2019), pp. 12966-12974, 10.1021/acs.jpcc.9b03983

26) T. Navizi, E. Salahi, M. Ghafari, I. Mobasherpour. Influence of Tiron concentration on dispersability and sintering behaviors of hydroxyapatite in an aqueous system. Ceram. Int., 36 (2010), pp. 1945-1949, 10.1016/j.ceramint.2010.05.015

27) B. Aladag, S. Halelfadl, N. Doner, T. Maré, S. Duret, P. Estellé. Experimental investigations of the viscosity of nanofluids at low temperatures. Appl. Energy, 97 (2012), pp. 876-880, 10.1016/j.apenergy.2011.12.101

28) G. Raza, M. Amjad, I. Kaur, D. Wen. Stability and aggregation kinetics of titania nanomaterials under environmentally realistic conditions. Environ. Sci. Technol., 50 (2016), pp. 8462-8472, 10.1021/acs.est.5b05746

29) H. Gulley-Stahl, P.A. Hogan, W.L. Schmidt, S.J. Wall, A. Buhrlage, H.A. Bullen. Surface complexation of Catechol to metal oxides: an ATR-FTIR, adsorption, and dissolution study. Environ. Sci. Technol., 44 (2010), pp. 4116-4121, 10.1021/es902040u

30) D. Vasudevan, A.T. Stone. Adsorption of 4-Nitrocatechol, 4-Nitro-2-Aminophenol, and 4-Nitro-1,2-Phenylenediamine at the Metal (Hydr)Oxide/Water Interface: effect of Metal (Hydr)Oxide Properties. J. Colloid Interface Sci., 202 (1998), pp. 1-19, $10.1006 /$ jcis. 1998.5422

31) G. Trefalt, I. Szilagyi, M. Borkovec. Poisson-Boltzmann description of interaction forces and aggregation rates involving charged colloidal particles in asymmetric electrolytes. J. Colloid Interface Sci., 406 (2013), pp. 111-120, 10.1016/j.jcis.2013.05.071

32) J. Farner Budarz, A. Turolla, A.F. Piasecki, J.-Y. Bottero, M. Antonelli, M.R. Wiesner. Influence of aqueous inorganic anions on the reactivity of nanoparticles in TiO2 photocatalysis. Langmuir, 33 (2017), pp. 2770-2779, 10.1021/acs.langmuir.6b04116

33) G. Zanaboni, A. Rossi, A.M.T. Onana, R. Tenni. Stability and networks of hydrogen bonds of the collagen triple helical structure: influence of pH and chaotropic nature of three anions. Matrix Biol., 19 (2000), pp. 511-520, 10.1016/S0945-053X(00)00096-2

34) J.L. Trompette, M. Meireles. Ion-specific effect on the gelation kinetics of concentrated colloidal silica suspensions. J. Colloid Interface Sci., 263 (2003), pp. 522-527, 10.1016/S0021-9797(03)00397-7

35) S. Sáringer, P. Rouster, I. Szilágyi. Regulation of the stability of titania nanosheet dispersions with oppositely and like-charged polyelectrolytes. Langmuir, 35 (2019), pp. 4986-4994, 10.1021/acs.langmuir.9b00242

\section{Glossary}

DLS: dynamic light scattering TGA: thermogravimetric analyses PAA:

polyacrylic acid

PSS: polystyrene sulfonate

PDADMAC: polydially dimethyl ammonium chloride

PAMAM: polyamido amine dendrimer

XRD: X-ray diffraction

BET: Brunauer-Emmett-Teller

SEM: Scanning electron microscopy TEM: Transmission electron microscopy IEP: isoelectric point 


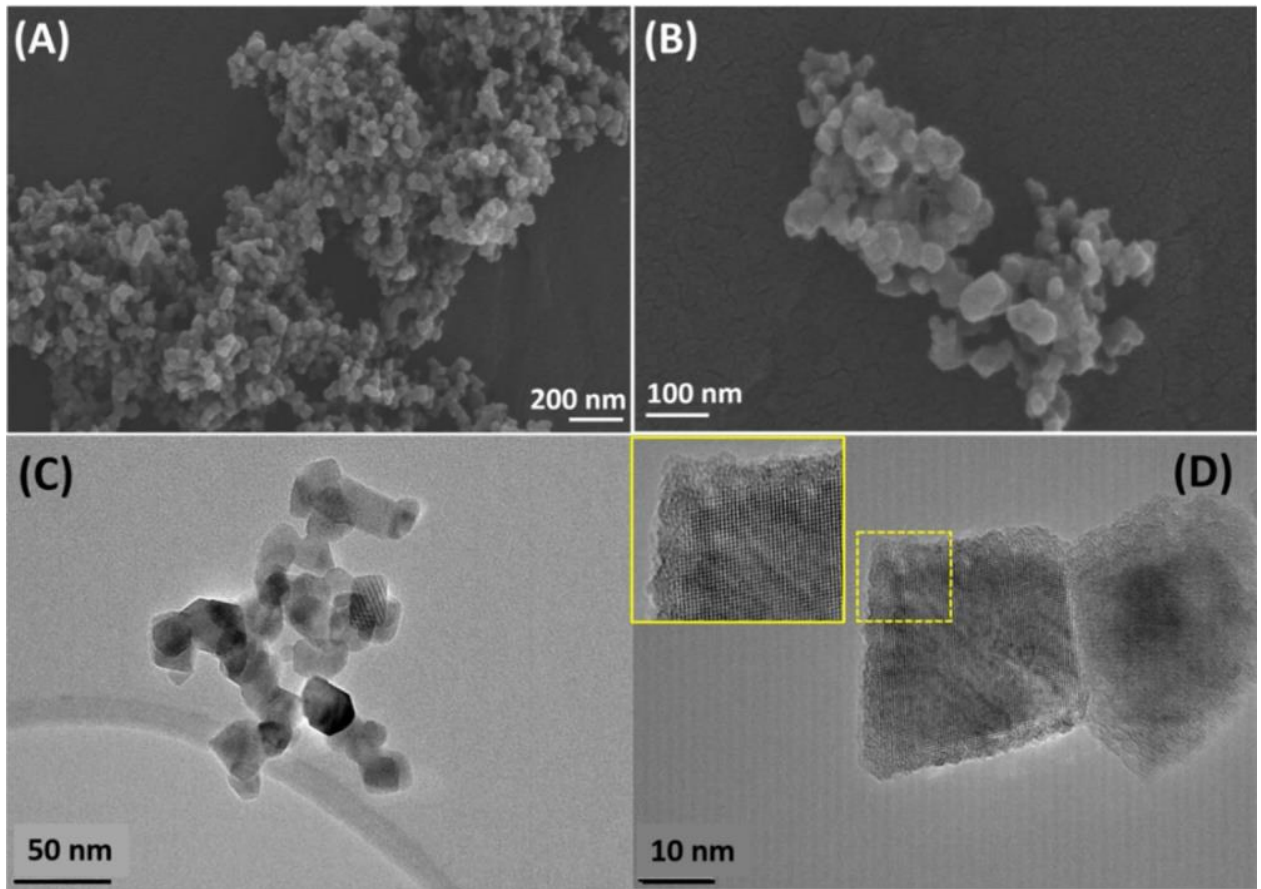

Fig. 1. (A, B) Scanning emectron microscopy (SEM) and (C, D) Transmission electron microscopy (TEM) images of TiO 2 P25 nanoparticles.

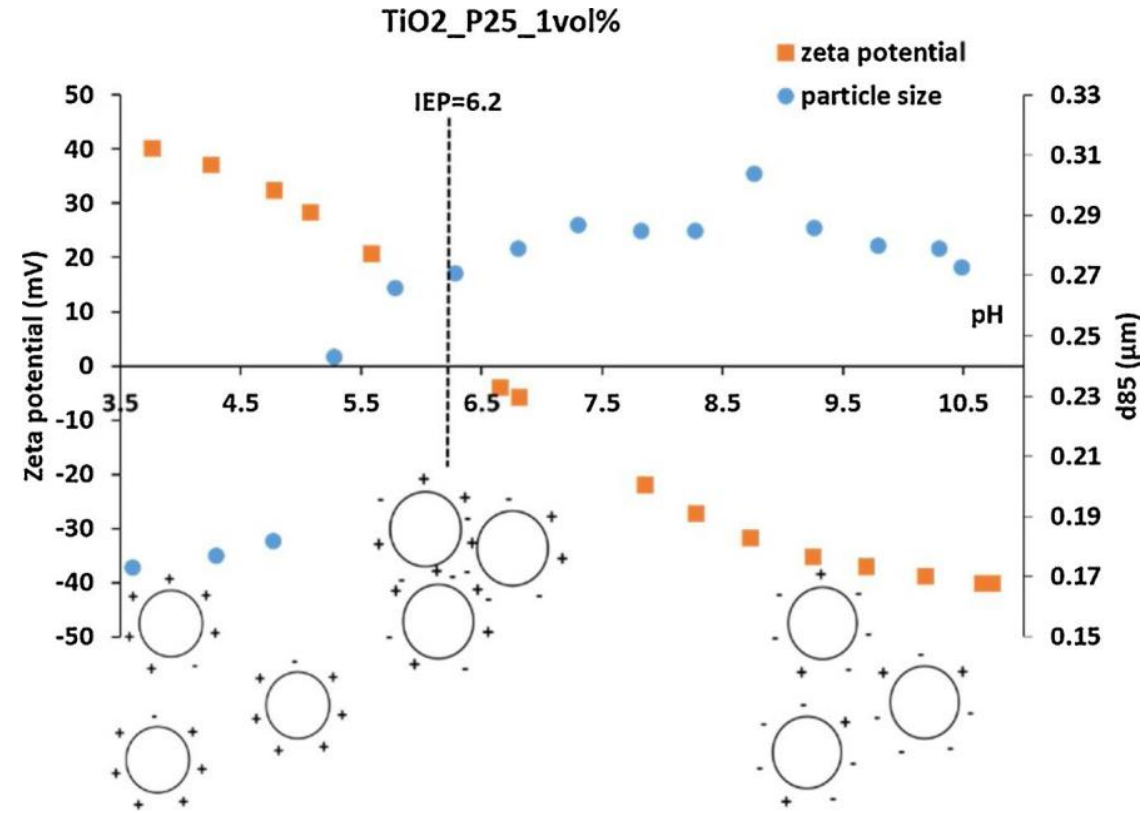

Fig. 2. Zeta potential titration and particle size measurements of $\mathrm{TiO}_{2} \mathrm{P} 25$ as a function of pH measured by acoustophoresis. 


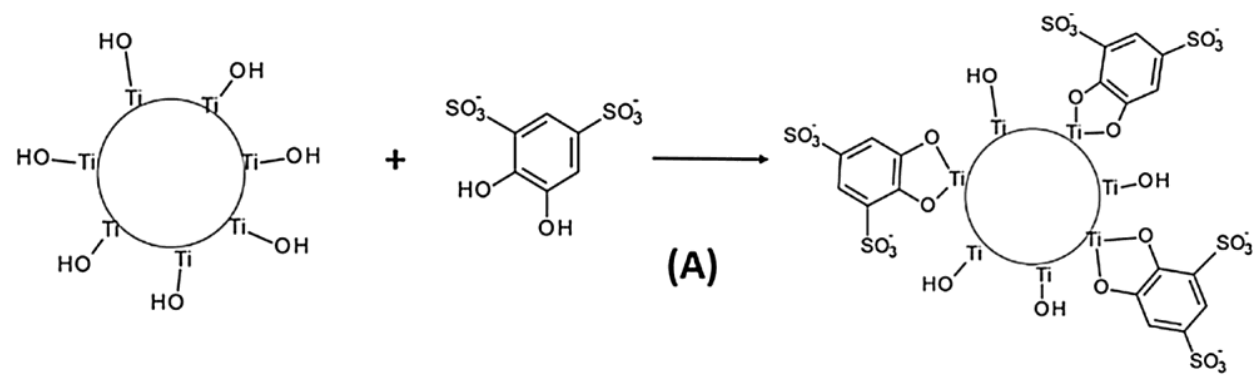

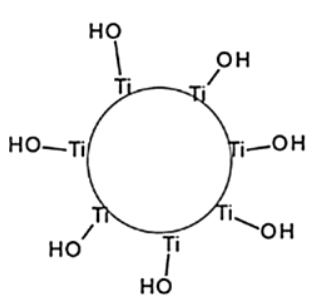<smiles>NCCc1ccc(O)c(O)c1</smiles><smiles></smiles>

Fig. 3. Schematic representation of (A) Tiron and (B) Dopamine chemisorption onto titania nanoparticles.
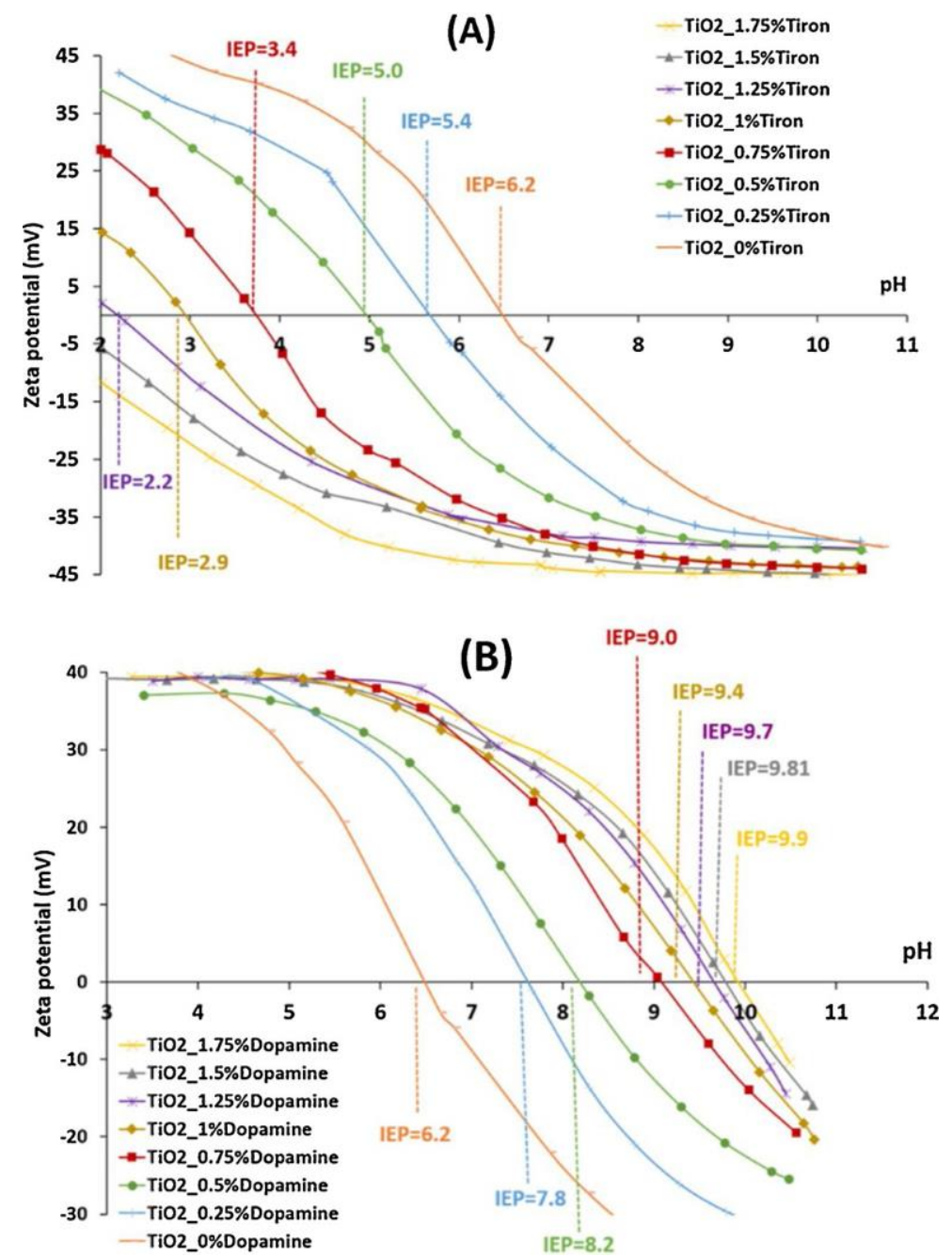

Fig. 4. Zeta potential measurements of (A) Dopamine -modified $\mathrm{TiO}_{2}$ nanoparticles and (B) Tiron-modified $\mathrm{TiO}_{2}$ nanoparticles $\left(\mathrm{TiO}{ }_{2}\right.$ suspension, 1 vol\%, NaCl $10^{-2} \mathrm{M}$ ). 

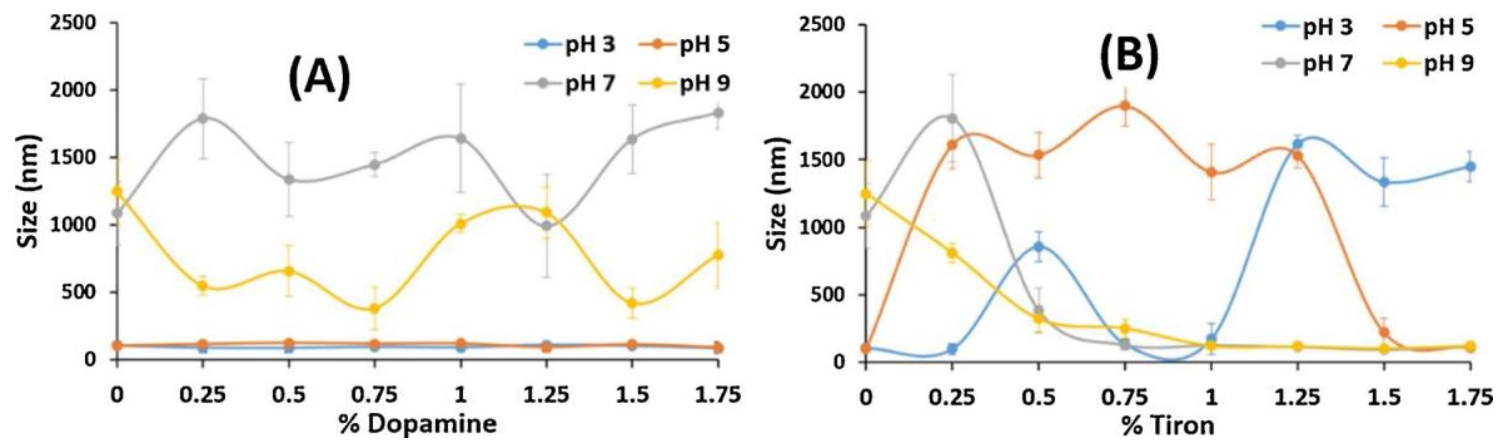

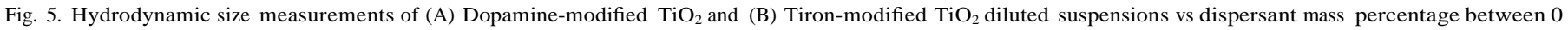
and $1.75 \mathrm{wt} \%$ and at four different $\mathrm{pH}(\mathrm{pH} \mathrm{3,5,7}$ and 9).
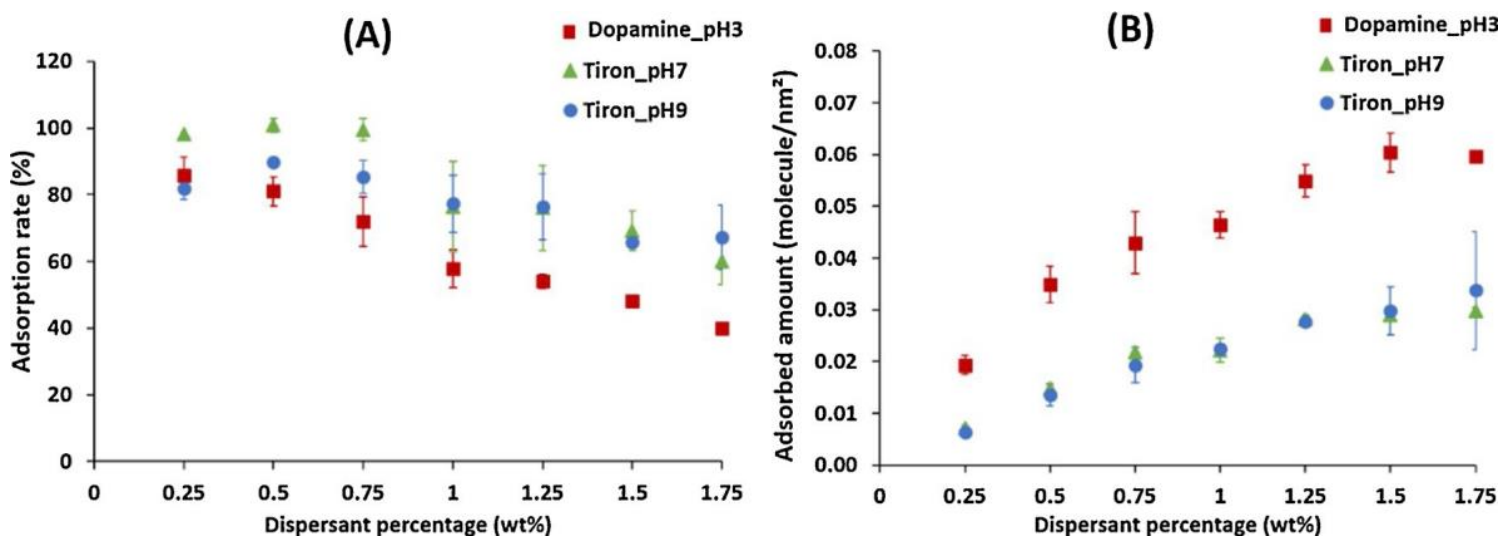

Fig. 6. (A) Adsorption rate and (B) adsorbed amount of Dopamine at $\mathrm{pH}=3$ and Tiron-modified titania at $\mathrm{pH}=7$ and $9\left(24 \mathrm{~h}, 25^{\circ} \mathrm{C}\right)$.

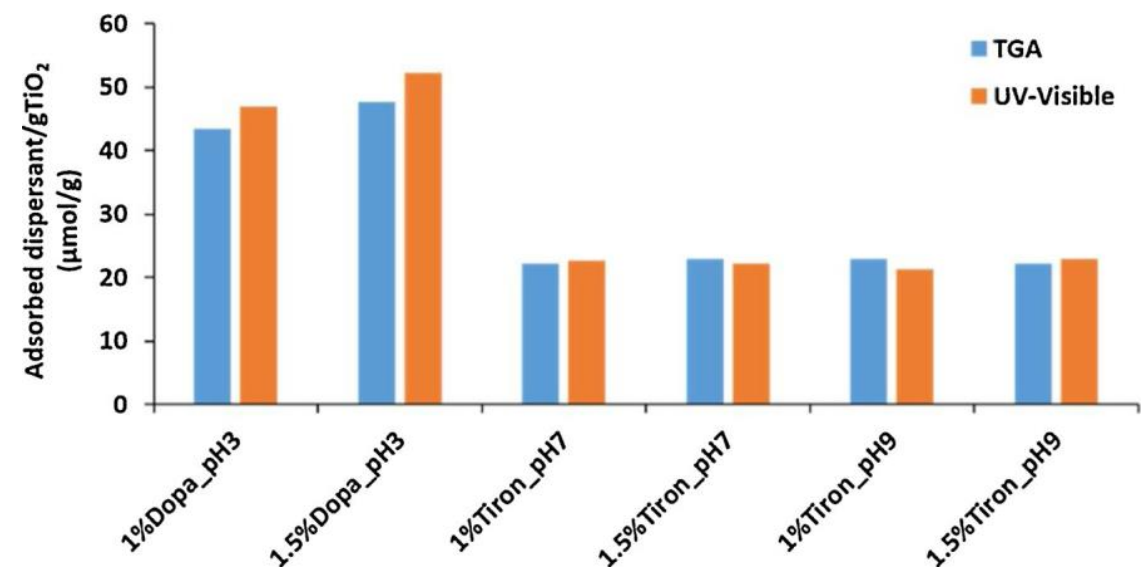

Fig. 7. Comparison of the adsorbed amount of Dopamine and Tiron obtained by TGA and UV-vis methods for six different formulation. 

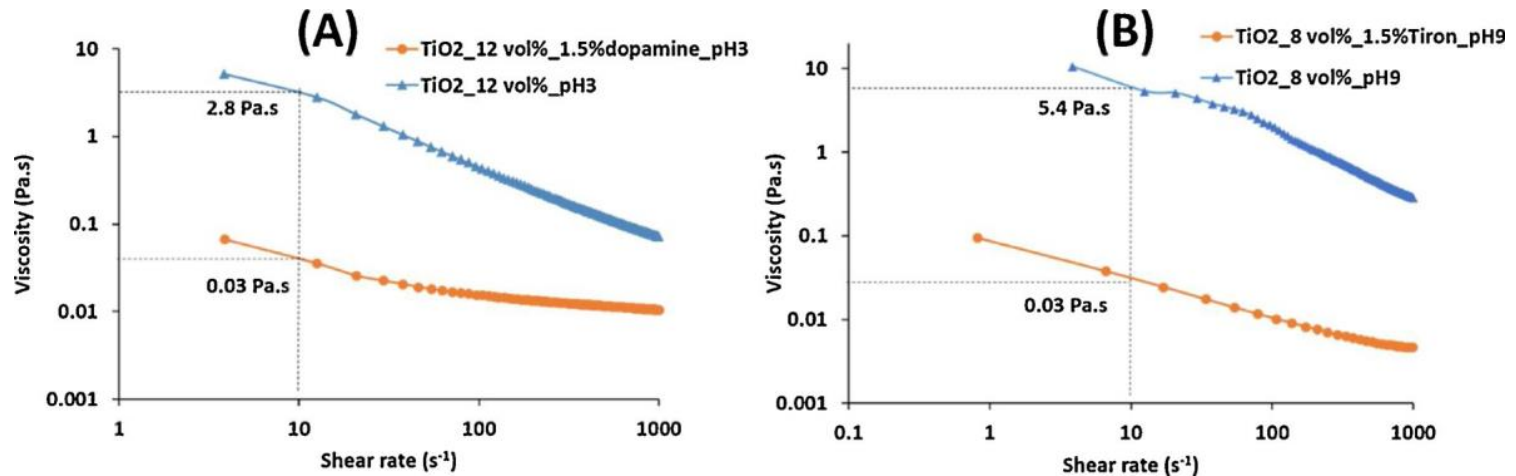

Fig. 8. Viscosity vs. shear rate for (A) bare and Dopamine-modified titania (12 vol\%, pH3) (B) bare and Tiron-modified titania (8\%vol, pH9) (imposed shear rate 01000 Pa.s).
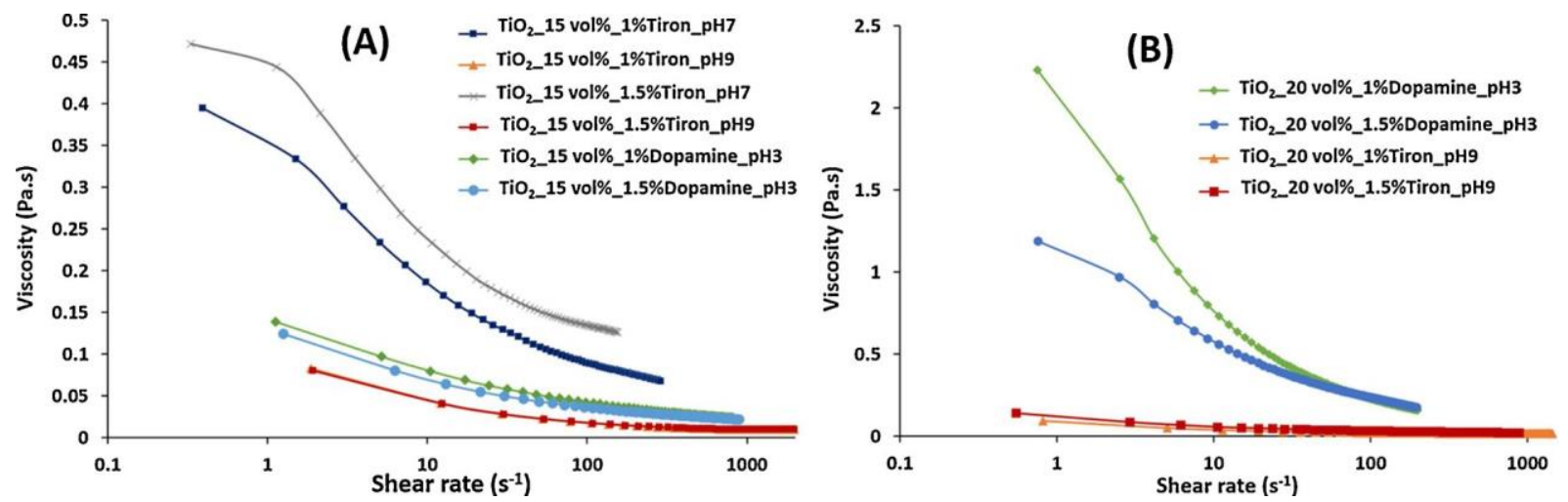

Fig. 9. Viscosity measurements as a function of shear rate of (A) Tiron/Dopamine-modified titania suspension $\left(15\right.$ vol\%, $\left.25{ }^{\circ} \mathrm{C}\right)(\mathrm{B})$ Tiron/Dopamine-modified titania suspension $\left(20 \mathrm{vol} \%, 25^{\circ} \mathrm{C}\right)$ at fixed stress $(0-20 \mathrm{~Pa})$. 